\title{
Pure Listening Training-A Tentative Innovation of English Learning
}

\author{
Jianhe Ma \\ School of Foreign Languages, Tianjin Polytechnic University, Tianjin 300387, China \\ Email: Jackmann08@yahoo.com.cn
}

\begin{abstract}
A worthwhile teaching and learning method means quite a lot for the fruitful study. As a science of cultural communication, the language acquisition involves various aspects such as listening, speaking, reading, writing and translating, etc. Though the traditional reading training makes the language learners comparatively skillful in their practice of reading, writing and translating, it still fails to meet the needs for them to perfect their listening, speaking ability. Here the paper introduces another language learning method--pure listening training---hoping to provide some actual aids for the English language learners.
\end{abstract}

Index Terms - pure listening training, reading comprehension, innovation, English language study

\section{ORIGIN OF THE PERCEPTION}

The very common learning style of us is reading, that is to say, we mainly obtain the information by means of reading through eyes, based on which we imagine and understand something in the text. Here we shall discuss another way of getting necessary information--pure listening training. It is so named because here the language learners will mainly acquire information by means of listening in stead of reading. Concretely speaking, they will try to imagine and understand something chiefly through ears, which is also in agreement with the learning law of the language science.

Language communication lies in two basic ways -- oral form and written form. As a matter of fact, the latter should be more fundamental. In terms of the language history, the formation and use of oral language was much earlier than the written one. Seen from the approaches of language acquisition, we always acquire our mother tongue first through listening and speaking. And in the daily life, most of the communication task is conducted in the form of oral way. For a change of our traditional language learning style, we give the priority to pure listening training based on the language law. By means of this we may find later that some previously confusing problems will present no difficulty anymore.

\section{THEORETICAL FOUNDATION}

The pure listening training is in some degree the same as the present listening and speaking course. But the present listening and speaking course is still low in efficiency because in the teaching course the students are quite passive in their actual listening practice because the teacher constantly controls them throughout almost the whole period. Here the pure listening training mainly focuses on the personal active study of the students, which is quite a unique perceiving, recognizing and learning style with the students personally, fully absorbed in it.

The mind effect theory: the pure listening training style of English learning is not only a studying activity, but also a mental recognition process, because the result will be directly related to the changes in the mind. The mind effect means the series of psychological reactions that have cropped up when most people meet with the same stimulus. And in the pure listening training, the audio and video elements will help to adjust and promote the students' analysis and understanding.

Modal and pragmatic theory: the language is the vehicle of information communication, a sound understanding and expressing can not do without the actual supplementary modal factors of the speakers. The definition of modal theory first came from Layence, who insisted that the modal factors reflected the attitudes of the speaker to the thing he had mentioned. It was not only related to the supplementary use of the modal verbs and modal adverbs such as "frankly, fortunately, possibly, wisely, etc.", but also related to the understanding of the speaker's subjective feeling. In some degree, the subjective factors can be regarded as the basic norms for modal measure (Palmer, 1986, P.16). Therefore, we can see here that the traditional reading style without the company of modal factors is bound to be imperfect, whereas the pure listening training has overcome the disadvantages in question.

Theory of Dialogue: We could only get half the result with twice the effort if we try to learn the language in the case of lacking audio and video settings. Though the Language can also be classified as a science, it is by far less rigid and precise than the natural science, only because it is the direct result of human life activity and is greatly influenced by human life habits, social customs and even personal preferences. Therefore, the language study lacking of situational settings is sure to meet lots of barriers in its actual learning and using.

The theory of dialogue from Bakhtin: the Russian arts theorist provides a practical support for language audio and video comprehension. He argues that Bakhtin (1992, cited in Zhai Tingting, 2009) insists "communication by means of 
dialogue represents the real value of the language itself'. In daily life, the actual conversations, such as showing agreement or disagreement, affirmation or negation, asking or answer, form the practical dialogue (ibid). All these relationships between the languages will be presented to the learners in the forms of three-dimension and many perspectives, and thus the language study becomes many - involved and efficient.

\section{OPERATING SEQUENCE}

\section{A. Choices of the Learning Materials}

S. D. Krashen thought that no one can actually acquire the language unless he has obtained enough comprehensive language input, i.e. the comprehensive language input is the only way to guarantee the acquisition of the language. This is what we call the theory of Krashen's language input. The comprehensive input means the amount of language input which is slightly more difficult than what the learners can understand. In the formula, it is like $i+1$, and here " $i$ " stands for the present language ability of the learners and "1" stands for the language input slightly more difficult than what the learners can understand. The language input should be neither too difficult nor too easy; otherwise it is quite impossible for the learners to get the ideal language input.

Therefore the choice of the textbook for the pure listening training is rather significant, it must follow the principles: (1) As a textbook, it must be characterized by profound knowledge, corresponding interest and arts features in the content. Only in this way can the students be deeply appealed to and are ready to study. (2) The text should be accompanied by closely related audio and video materials, illustrated with live moving pictures. Thus, it may meet the needs of the students in listening comprehension.

\section{B. Line of Thought}

The learning style of the pure listening training must feature a unique or, punctually speaking, a more flexible and abundant mode of thinking: perceiving and acquiring language mainly by means of listening activity. So the appropriate method of language study must guarantee the accomplishment of these norms.

\section{a. Identifying the Setting, Interpersonal Relationship and Mood in It}

Through repeated listening, the learners try to identify the creating settings of the writing with the help of the language used and the music involved, the time and location of this very happening, to identify the possible interpersonal relationships and their mutual attitudes under the help of the tones of the speech, the use of body languages and even the expression on the faces. By doing so, the learners can perceive the rhyme of the language; perceive the inseparable unity of the language and its context, and thus the learners may get more instructive senses of the language.

\section{b. Identifying the Topic and Main Idea of It}

To finish these assignments, the learners must capture quite a lot of related key words and expressions, to make sure what the writing is talking about and what its purpose is through continual listening practice. This activity not only connects with the knowledge information of the text involved, but also connects with personal experience of the learners which is not directly related to the task. And thus they can make the learners associate and analyze the situation and enjoy a study style of three -dimension.

\section{c. Making Corresponding Hypotheses, Prediction and Inference}

During the studying style of the pure listening training, every factor in the sentence will stroke on the nerve of the learners, for example, each plot in the writing, the sentence pattern, and even the tones and the intonations of the sentence spoken. Therefore the learners will constantly make the hypothesis, prediction and inference about the inducing factors, developing stages and the further result of the whole incident. Compared with the passive listening activity, learners are quite active in this studying mode. Here the learners are the masters of their studying practice and control all the studying activities. So the style of the pure listening training does not make a direct dive for the result, but aims at listening and comprehension process itself. This is more close to the natural law of language studying, and can ensure the learners to get twice the result with only half effort, and the learners can take in all kinds of precious knowledge accomplishments, such as the instinctive feeling for the language, listening, analysis and evaluating ability.

\section{PReVIEW of the Possible Result of the Pure Listening Training}

Once the pure listening training style goes into the actual language acquisition activity, the foreign language study will go into a new learning state.

First, it brings innovation to the language study environment. Instead of the previous way of perceiving necessary information by means of eyes, which is typical of reading and memorizing mechanically, this kind of pure listening training style is featured by the co-occurrences of audio and video captions. The change of learning style is sure to stimulate the enthusiasm of the learners for language study. The traditional teaching and learning style is boring and full of oppressed feeling mainly because the learning activity is almost completely dominated by reading, memorizing mechanically, and repeatedly writing. Lacking the chances to contact with the pure pronunciation of the English native speakers, it seems that they will never be able to acquire the real tones and intonations of them, and consequently they will lose the last self-confidence for the learning activity. 
Second, another advantage of the pure listening training style lies in its unconscious devotion to the cultivation of the sense of the language. The language sense is a very significant ability which can guide the language study instinctively as if it were a kind of unknown supernatural power. Without the help of language sense, we could hardly get the inspiration to learn it well. However, the acquisition of language sense can only find its way in the day after day listening training and in some degree it is invisible and unconscious.

Third, the pure listening training can also strengthen the reading comprehension ability. Just as what we have discussed above, this method can meet the needs of students to recognize the words and sentences from many related aspects as pronunciation, pictures, structures and modal details, to identify the writing backgrounds, the actual interpersonal relationships, and the speaker's real attitudes, to identify the topic and its main ideas, and make reasonable hypothesis, prediction and inference of something in the studying material. After the repeated training, the learners' comprehensible ability could not remain at the shallow level any longer. After a period of practice, the original most difficult assignments in their study -- reading comprehension, etc-- will present them no problems.

Fourth, it can make up for the shortage in the students' listening ability. The very vital inability in students' listening practice is the requirement for filling the blanks, writing the missing information or even the whole paragraph. In the CET-4, the students are required to write the actual words, the sentences and even whole paragraph after having finished listening to the text, but this is really what they feel helpless. The reason lies in that in the usual study they mainly focus on reading comprehension in stead of listening comprehension. At first sight, they feel the words quite familiar to them and as if they knew the meaning quite well, but when the foreigners speak them out, they are not sure what words are the ones they are saying, especially when they are spoken together with the various intonations. What's more, some students are not exactly clear about the very pronunciation of some words, the question itself has already been tricky, let alone the identification of the background information, interpersonal relationships and even some other details.

At last, the pure listening training style can also help to improve the oral English effectively. As we all know, if we have had enough listening training practice, it is very natural for us to speak it out spontaneously. If we had enough listen training, we are easier to perceive the meaning between the lines, and subsequently we will be good at the thought expressing and the corresponding expressing techniques. This basically gives us the logical explanation of the embarrassment why it seems we often can not easily understand the foreigners effectively. It is because we have listened too little, it is not possible for us to identify the words they said or quickly connect what they said with the words we have suspected to be.

\section{CONCLUSION}

Learning by means of the pure listening training is a better way for foreign language study, especially in the situation of lacking corresponding language context. It happens to coincide with the logic of language learning, and helps to eliminate many troublesome problems like the bottom ability indispensable for English listening, speaking, analyzing, understanding, and writing. But we still confront great challenges. (1) We need to make good preparation for the textbooks needed. We lack such ideal existing textbooks throughout the country at the moment, which should be compiled as soon as possible. (2) The actual levels of the students' foreign language ability are quite different from each other even in the same class. The teacher who is in charge of the language teaching often finds it hard for him to take both the top students and the bottom ones into consideration at the same time. If we really want to escape the bad fate early, we must change the teaching and learning style fundamentally, that is to say, to put the pure listening training method into practice in no time.

\section{REFERENCES}

[1] He Yingyu. (2006). Pragmatics. Shanghai: Shanghai Foreign Language Education Press.

[2] Krashen, S. D. (1982). Principles and Practices in Second Language Acquisition. Oxford: Pergamon Press.

[3] Liu Chuan. (2005).The Cognitive Theory for the Interpretation of Conversational Complicature: Foreign Languages in China, 2,44-46.

[4] Liu Yuhong. ( 2006). Theory of Dialogue of Bakhtin and the Clause Pragmatics Study: Foreign Languages in China, 3,21-22

[5] Palmer, R. (1986). Mood and Modality. Cambridge: Cambridge University Press.

[6] Wang Peiguang. (2005). Language Sense and Language Ability .Beijing: Beijing University Press.

[7] Yu Xiaodan. (2005). Foreign Language Teaching and Research. Changchun: Jilin University Press.

[8] Zhai Tingting. (2009). On Bakhtin's Dialogue Communication Theory. Social Sciences Journal of Colleges of Shanxi, 4,21.

[9] Zhang Zaihong. (2004). Adopting a Strategy-based Approach to Teaching Listening Comprehension: Celea Journal, 10,27-29.

Jianhe Ma was born in Baoji, shaanxi, China in 1965. He received his M.A. degree in Foreign language linguistics from Xidian University, Xi'an, China in 2004.

$\mathrm{He}$ is now a lecturer in the school of foreign languages, Tianjin Polytechnic University, Tianjin, China. His research interests include semantics, pragmatics, applied linguistics, and college English teaching. 